\title{
Role Of Small Innovative Enterprises In Training Young Scientific Personnel In Russia
}

\author{
Liudmila P. Goncharenko \\ SRI Innovative economy, \\ Plekhanov Russian University of Economics, \\ Moscow, Russia \\ e-mail: inn.invest@mail.ru
}

\author{
Sergey A. Sybachin \\ SRI Innovative economy, \\ Plekhanov Russian University of Economics, \\ Moscow, Russia \\ e-mail: sybachin.sa@ rea.ru
}

\author{
Gregory Khachaturov \\ department of organizational and managerial innovations, \\ Plekhanov Russian University of Economics, \\ Moscow, Russia \\ e-mail: khachaturov.g@gmail.com
}

\begin{abstract}
This article describes the current system of the young scientific personnel training in Russia and puts emphasis on the need to strengthen practical training thereof. As one of the ways to solve this problem, small innovative enterprises are considered as a possible link between Science and Business, which has necessary opportunities and capabilities.
\end{abstract}

Keywords - small innovative enterprises; young scientific personnel; training system.

\section{INTRODUCTION}

The issue of young scientist training within the country is becoming increasingly important every year. And now the task, posed to universities and research institutions, aims to ensure "extended reproduction", rather than simple replenishment of natural and mechanical personnel outflow due to natural aging. This "reproduction", to be provided through improved qualitative and quantitative characteristics of the young scientific personnel training, is called upon to respond to today's challenges which any economy is facing, i.e.:

1. to substitute "morally obsolete" scientific personnel, which appear due to exponentially expanding scope of information and sci-tech progress acceleration;

2. to replenish natural outflow of scientific personnel;

3. to prevent and replenish mechanical outflow of young scientific personnel, which is created through offering of better research conditions for the most promising scientists by foreign countries;

4. to create a "class" of flexible young scientific personnel, who is capable to rapidly change scientific research vectors as a response to dynamic structural changes in the economy as well as to deep immerse in a new direction for creating teams, working at scientific sector interfaces;
5. Phase out imported goods, i.e. develop domestic analogues to foreign products, which have to be not only competitive with their foreign origins, but also, in certain cases arisen as a result of an unstable economic situation, to completely substitute imported goods.

Responding to these challenges without prior creation of a consistent and interrelated scientific personnel training system is impossible. At the present stage, the critical issue in this system is to combine both theoretical and practical training. And namely the practical side represents the greatest complexity for implementation.

\section{CONCEPT DEVELOPMENT}

In Russia, the issue of practical, let alone entrepreneurial, training of young scientific personnel is extremely poorly developed. Against the backdrop of shrinking scopes of scientific personnel training in general, this issue is extremely acute. In this regard, it's necessary to improve the education system itself; for this purpose, it's expedient to pay attention to foreign education systems, in particular, to those which differ from the Russian one. Of these systems, the education system of Germany, which notably differs from the Russian one, and the education systems of Mongolia and Kazakhstan, with the latter being the CIS member state, are of considerable interest.

According to the official Russian statistics (Rosstat data) [1], 25992 post-graduate students graduated from postgraduate schools in 2016, and only 3730 post-graduates managed to defend a thesis, i.e. $14.35 \%$ of the total. For comparison, in 2010 these figures were 33763 and 9611, respectively, i.e. $28.47 \%$. In the period from 2010 to 2016 , the number of post-graduate students dropped by almost $30 \%$, and the number of those who defended a thesis fell more than 2.5 fold. See Fig. 1 for the trend. The situation with the training of 
doctors of science looks better; however it still remains disappointing. In 2016, 1346 persons graduated from doctorates as compared to 1259 persons in 2010, but the number of graduates, who managed to defend a doctoral thesis and received the doctor degree, dropped more than twice, from 336 persons in 2010 to 151 persons in 2016. See Fig. 2 for the trend. Hence, it can be concluded that the efforts and opportunities of the existing educational system in Russia are not sufficient for young scientific personnel training; this is felt specifically strong while training doctoral students.

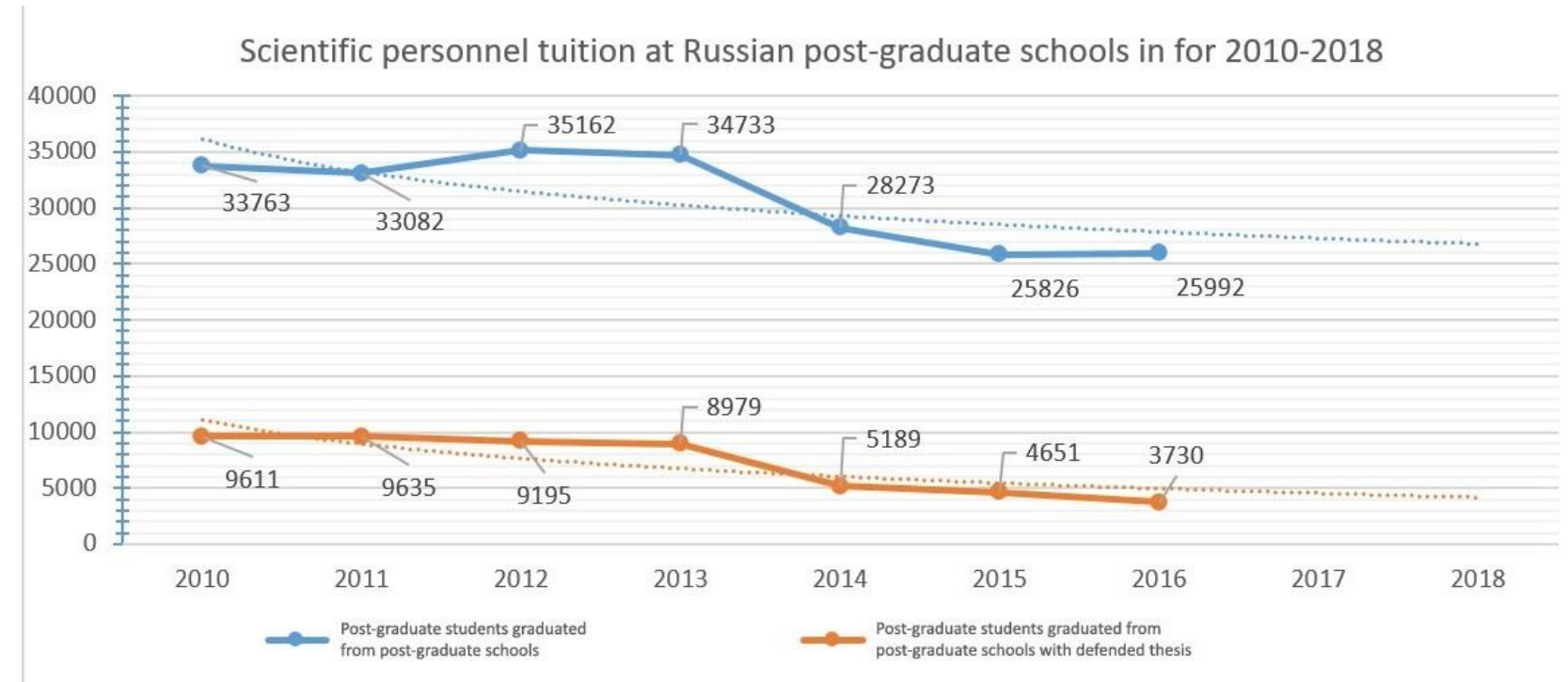

Fig.1. Scientific personnel tuition at Russian post-graduate schools in 2010-2018 (this figure was plotted by the author based on data presented in [1]; data for 2017 and 2018 were obtained by plotting a logarithmic trend)

Training of research associates in doctoral studies of Russia in 2010-2018

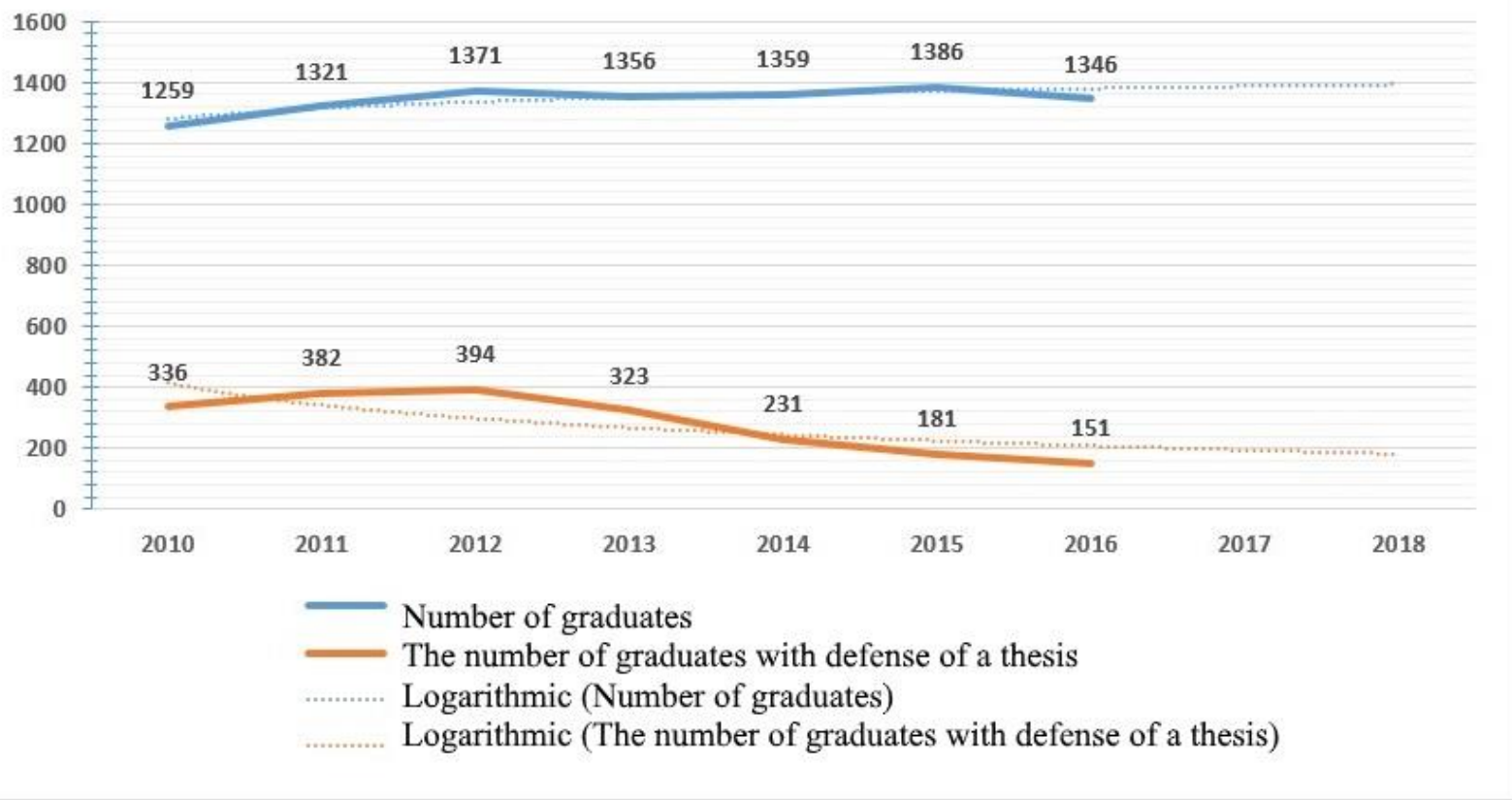

Fig.2. Scientific personnel tuition at Russian doctorates in 2010-2018 (this figure was plotted by the author based on data presented in [1]; data for 2017 and 2018 were obtained plotting a linear trend) 


\section{Tuition of bachelors, masters and doctors of sciences in Germany in 2010-2018}

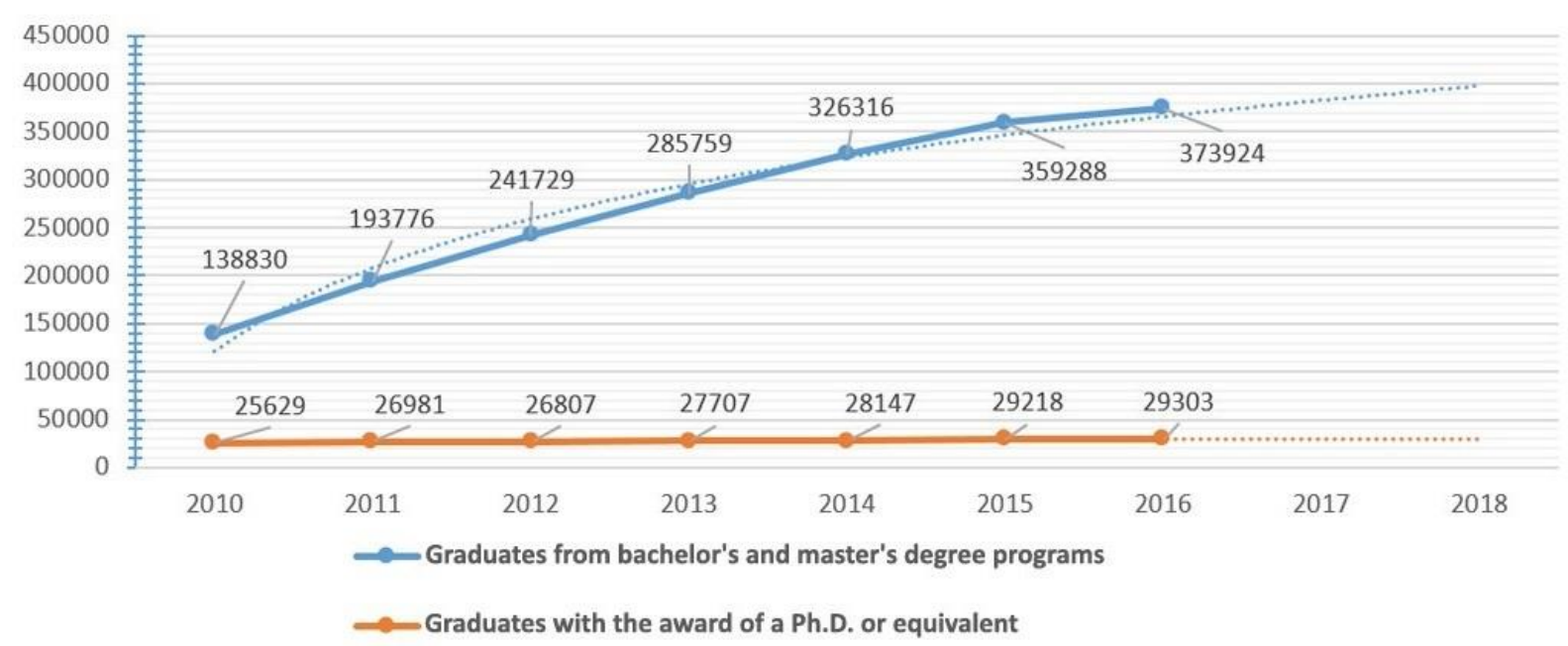

Fig. 3. Tuition of bachelors, masters and doctors of sciences in Germany in 2010-2018 (this figure was plotted by the author based on data presented in [2]; data for 2017 and 2018 were obtained by plotting a logarithmic trend)

Partially, this result is explained by a two-tier scientific personnel training system, existing in Russia. Admission to doctorates is impossible without the availability of a philosophy doctor (Ph.D.) in science. Fig. 1 and Fig. 2 demonstrate a clear tendency of a multiple reduction in the number of people at each subsequent stage: training at (and graduation from) post-graduate school - graduation with a thesis defended - doctorate training (and graduation from it) graduation with a thesis defended. Some of the reasons arise from the following:

1. Two-level system greatly extends the terms of young scientific staff preparation.

2. Lack of strong motivation for transition to the second level of education after receiving the Ph.D. degree.

3. Trainees are forced to go to work due to an existing difficult economic situation and a lack of sufficient science funding with rather extended training periods; in total, this does not contribute to the progress of training.

4. Formally, the system is divided into two clearly defined levels; however, if you move away from formal documents, it is possible to draw a boundary between the levels, which can be characterized as follows: "methodological recommendations" and "methodological base improvement". From the viewpoint of the market, the practical component in both cases is weak and does not assist in the young scientist training to adapt to present-day economy realities.

Considering the above, the young scientific personnel training system should be improved in the following areas: raise students' motivation to complete training programs with the defense of the thesis and continue; improve science financing mechanisms; develop practical experience in commercializing developments and conducting commercial research by young scientists. After resolving the top-priority issues, it will be possible to concentrate efforts on responding to modern challenges.

Turning our view to the foreign experience, let us first pay attention to Germany. In practical training of young people, the educational system of Germany is far ahead. In their system, training of young scientists occupies a special place. This stage is accessible only upon graduation from higher schools, the admission to which requires special training either in gymnasiums, or additional tuition at vocational schools. It is important to note that gymnasiums and vocational schools, in addition to basic vocational training, also include practical training with the involvement of business representatives and practice at enterprises. This training starts early, at the $10^{\text {th }}$ class (German educational system involves a 13-class educational system). Later, at higher schools, profiling is intensified and the educational process is concentrated on the study of specific disciplines, strictly corresponding to the chosen professional vector. In Germany, post-graduates may be admitted to doctorates only if they have a diploma of graduation from a higher school. It is also important to note that the scientific personnel training is organized in two stages: first stage assumes the defense of the thesis for obtaining a scientific degree of the Doctor of Science, and the second stage assumes passing a state examination for obtaining the status of the Professor-Teacher. The current young scientist training system in Germany is characterized by the statistics presented in Fig. 3.

The graph clearly shows a steady increase in the number of graduates in 2010-2014; in this period, the number of graduates, who completed bachelor and master training programs, grew 2.35-fold. Since 2014, the increase in the training scope began to slow down, and in the period from 
2014 to 2018, the number of bachelor and master trainees increased only by 47608 persons, i.e. by $14 \%$ only. This may be first caused by consistently proceeding structural changes, aimed at the intensification of the economy digitalization and the development of related areas. The graph also reflects a slight, but stable growth in the number of graduates with the degree "Doctor of Science", but in conjunction with data on the growing number of graduates from the bachelor and masters training programs, the situation is mixed. Every year, the number of bachelors and masters tends to decrease: e.g., in 2010 the number of graduated doctors of science was $18.46 \%$ of the total number of bachelors and masters, whereas in 2018 this ratio was only $7.84 \%$. Most graduates, having obtained professions which are in high demand on the market, prefer to go to work, rather than choose a scientific field and continue their education.

In Germany, any graduated young scientist generally has good practical skills and a narrow professional specialization; however, considering the digitization of the economy and intensive development of related areas, this kind of training brings both notable advantages and significant disadvantages: modern economy aims to strengthen interdisciplinary ties, which implies the need to also train specialists of a wider professional range.

\section{Tuition under the Bachelor, Master and PhD programs in Mongolia in 2010-2018}

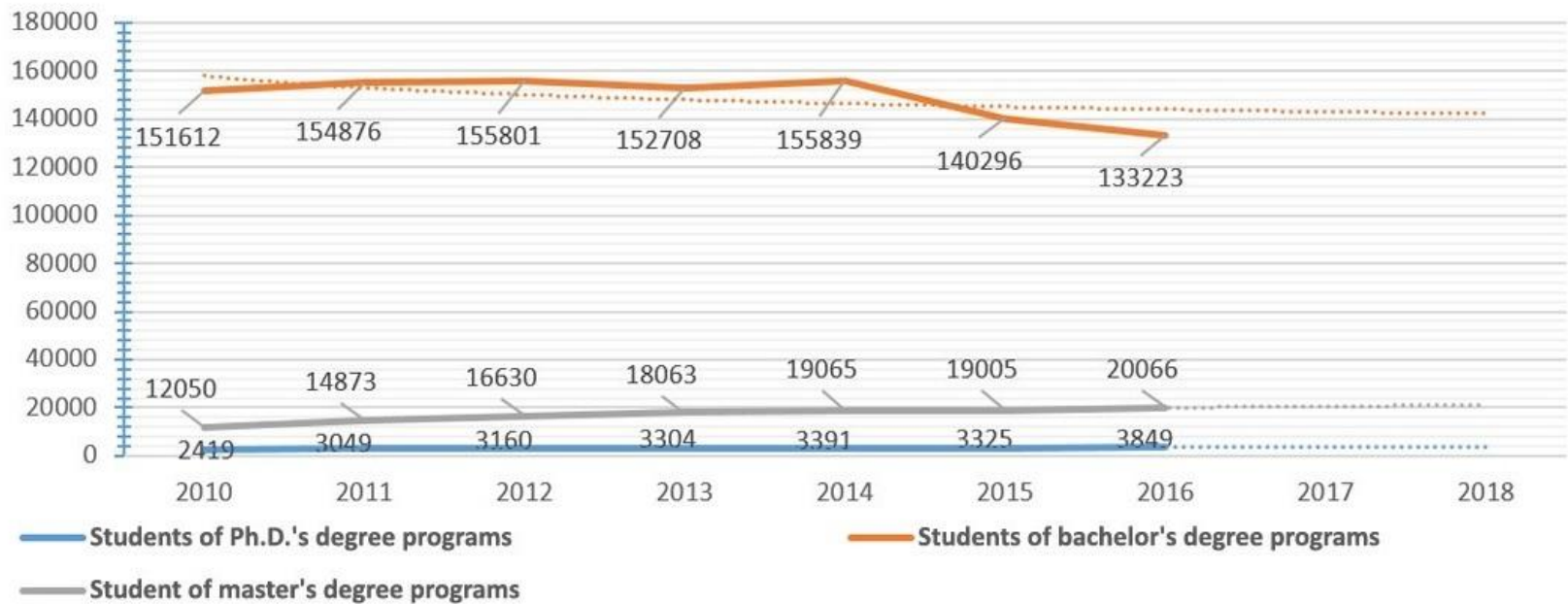

Fig. 4. Tuition under the Bachelor, Master and PhD programs in Mongolia in 2010-2018 (this figure was plotted by the author based on data presented in [3], data for 2017 and 2018 were obtained by plotting a logarithmic trend)

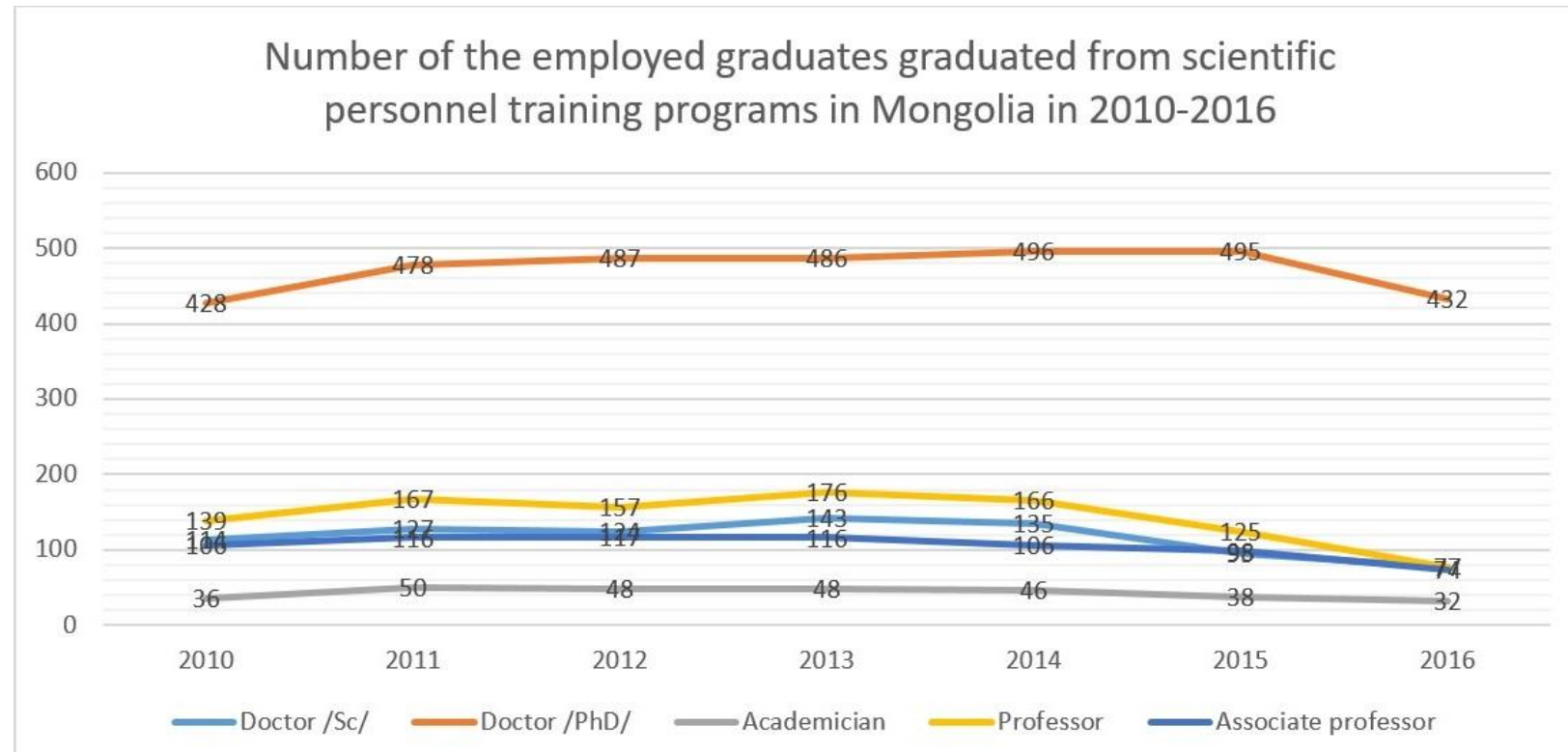

Fig. 5. Number of the employed graduates graduated from scientific personnel training programs in Mongolia in 2010-2016 (this figure was plotted by the author based on data presented in [3]) 
Then, let us review a scientific personnel training system in Mongolia. The Mongolian educational system also differs from the Russian one, but these differences are less significant. In terms of scientific personnel training, Mongolia uses a one-level training system, i.e. doctorates. Today, this system is characterized by the figures reflected in Fig. 4 and Fig. 5. As you can see, since 2014 the total number of trainees has declined due to a reduced number of applicants to the Bachelor's programs, and accounted for $8.79 \%$ in 2015 and $11.87 \%$ in 2016 . At the same time, the number of students enrolled in the Master's program and, most importantly, in doctoral programs, has grown. This is particularly noticeable for 2016, when the growth was $15.75 \%$, as compared to 2015 . However, contrary to the positive trend in scientific personnel training, very few people in the whole country are engaged as research personnel; furthermore, a negative trend in this area is observed (Fig. 5).

The one-level scientific personnel training system reflects a strong influence of the West. This kind of system allows a doctoral student to concentrate his efforts on resolving a specific scientific and practical problem without its fragmenting into levels and depth of research. However, for the country as a whole, this system creates significant risks of a mechanical depletion of young scientific personnel, since these scientists, being taught according to Western standards, are able to cooperate with Europe and move abroad, seeking for better scientific research conditions. For the world scientific community as a whole, the absence of artificial bureaucratic barriers to cooperation between scientists of different countries is a good opportunity, but for the national economy, given the previously identified problems, a real threat of the scientific personnel outflow is created. Also, training under a one-level system allows young scientists to enter the market faster and to be engaged in professional activities. In particular, in this system the vectors of dissertational research are not divided into more fundamental studies or less fundamental studies, they are split to practice- oriented and fundamental ones. Although this approach also brings a disadvantage, i.e. graduates of doctoral studies, who defended a thesis, received a Doctor in Science degree and entered the labor market, then leave research activities for one or another reason.

Kazakhstan also adheres to this one-level scientific personnel training system; results of application of this system are characterized by the figures presented in Fig. 7. At the same time, Fig. 6 shows that trends in the education system effectiveness in the both countries are similarly shaped. The most important points in these charts are as follows:

1. "Pyramidal" structures of educational systems in general, where fewer people pass to each subsequent level with significant multiple differences.

It is important to note the difference in the Mongolian and Kazakh training systems, since in Mongolia a greater number of bachelors, in percentage, continue their education in the magistracy after completion of Bachelor's programs, and likewise is true for the magistracy-doctorate transition. This indicates a greater motivation and interest in continuing education, including development in the research vector.

2. In terms of the scientific personnel training effectiveness, Kazakhstan demonstrates better results.

It can be seen from the chart that at a comparable number of students involved in doctoral studies, the number of graduates with a defended thesis is higher in Kazakhstan, than in Mongolia (in this case, an indirect indicator is the number of employed graduates from doctoral programs) (Fig.5 and Fig.7), which indicates that young scientists in Kazakhstan are stronger motivated to obtain a degree and have appropriate opportunities for this. But at the same time, the percentage of those, graduating with a defense of the thesis, in relation to the total number of graduates of doctoral studies, tend to decrease. For example, in Kazakhstan this percentage was about $70 \%$ in 2010-2011, only $42.8 \%$ in 2012, and only $18.9 \%$ in 2016.

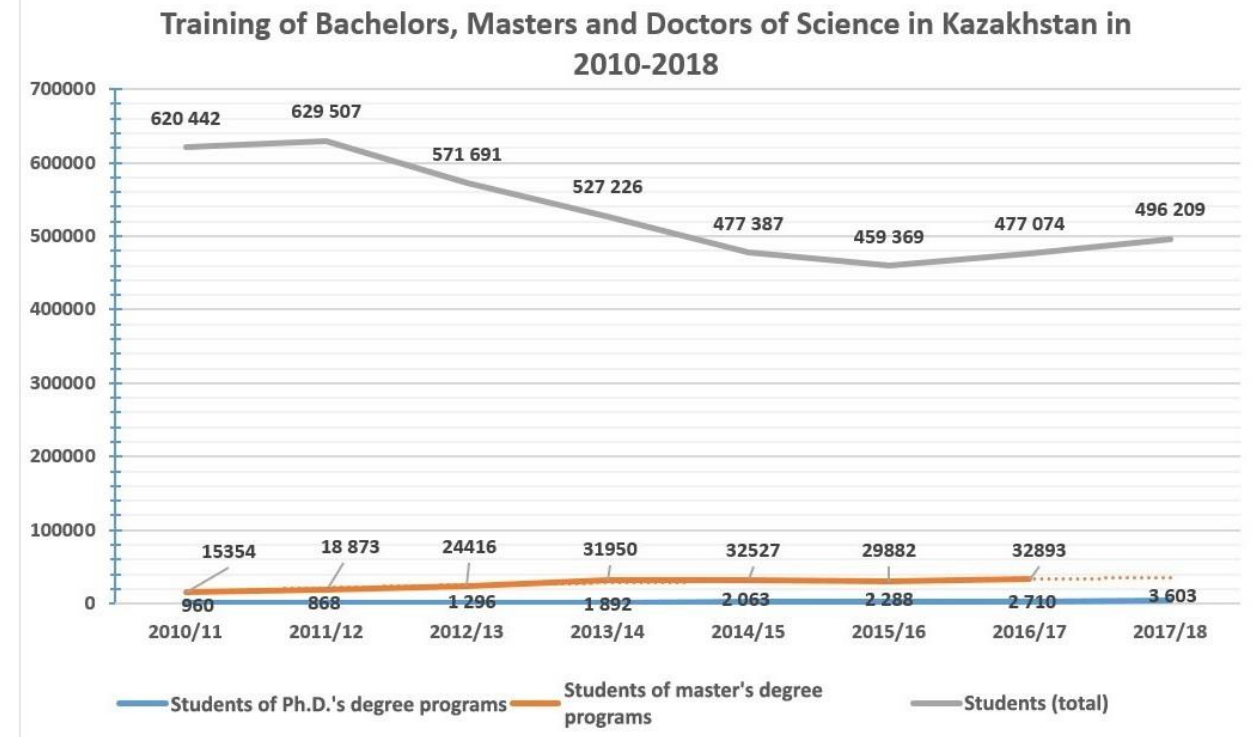

Fig. 6. Training of Bachelors, Masters and Doctors of Science in Kazakhstan in 2010-2018 (this figure was plotted by the author based on data presented in [4], part of the data were obtained by plotting a logarithmic trend) 


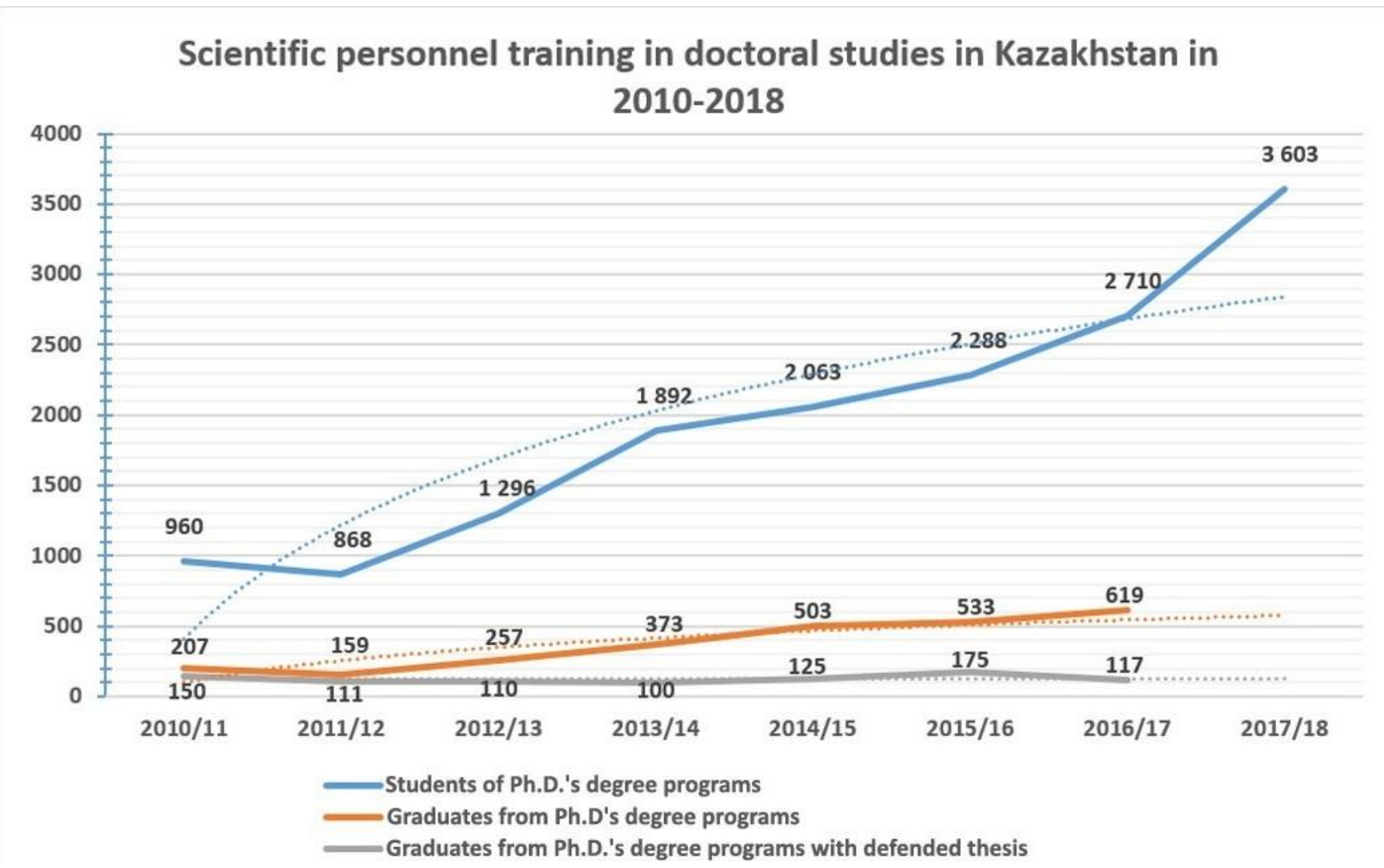

Fig. 7. Scientific personnel training in doctoral studies in Kazakhstan in 2010-2018 (this figure was plotted by the author based on data presented in [4], part of the data were obtained by plotting a logarithmic trend)

Based on prevailing trends and performance of the scientific personnel training systems in Mongolia and Kazakhstan, it can be concluded on the lack of a practical component and weak involvement of young scientific personnel in economic activities, characterized by a large number of graduates, who graduate from doctoral studies without defending their thesis and do not continue to work in the scientific field. This experience is extremely important for improving scientific personnel training system in Russia, as it focuses not only on the motivation of bachelors and masters to follow the young researcher's path, but also on the retention of trained young scientists in this path.

\section{RESEARCH METHODS}

In the framework of the task set in the article, it is necessary not only to develop recommendations, which will improve the existing young scientist training system in Russia, taking into account the accumulated domestic and foreign experience, but also to find a reasonable balance between practice-oriented training of young scientists, avoiding situations with inadequate preparedness in general, or training that forces young scientific personnel to leave the scientific sphere. Therefore, an interlink is required to join science and business and, at the same time, to allow young scientists to prepare themselves for work in a competitive market environment, and to continue their scientific research studies.
In Russia, small innovative enterprises (SIE) are called upon to be the above-mentioned intermediary, whose task is to implement in practice the intellectual activity results, obtained in higher educational institutions. Therefore, these small enterprises are the best basis for gaining practical knowledge by young scientists, which is open to all innovative solutions, has theoretical and practical support from senior scientific staff, as well as the support of a higher school education in business matters. Let's briefly describe the results, which can be achieved through an active involvement of small innovative enterprises on a national scale to resolve the previously identified issues (1-4):

1. Right from the student's bench, future young scientific personnel can start participating in the activity of small innovative enterprises, which, even in the process of obtaining higher education, contributes to the development of practical skills without interrupting the educational process, but being organically integrated in it. In addition to developing practical skills, students will acquire scientific understanding, since the activity of small innovative enterprises focuses on the intersection of scientific and practical areas, and this activity is carried out with the support of originators of the intellectual property that became the "core" of the small innovative enterprise.

2. Young scientists' motivation is formed in the course of business activity. They see practical results of their 
participation in research and development, its importance for the country's national economy, and also receive a worthy reward for their efforts. In total, this, alongside with the environment, makes them interested in continuing development in the scientific path and passing of subsequent training.

3. Being involved in the activity of small innovative enterprises, young scientists can receive appropriate remunerations, which allows them at least to smoothen to a great extent, if not to resolve in full, urgent financial issues.

4. Today, small innovative enterprises, being potentially one of the most active and dynamic players in the market, primarily because of its significant innovative component, are considered the most promising solution for adapting young scientists to the presentday economy realities.

The activity of small innovative enterprises within the frames of higher educational institutions may bring significant results. Acting through institutes, small innovative enterprises may adopt the strong practical experience of Germany, related especially to two issues:

1. Develop an "Enterprise-School" interface system to strengthen the profile and practical component already at the general secondary education level, which will contribute to the vocational guidance of schoolchildren.

2. Implement practical component in the young scientific personnel training, which, in particular, create incentives for further work in the scientific field, as well as for the transition to the next stage of training.

3. Provide the scientific sphere with additional funding, obtained due to commercialization of developments through the activities of small innovative enterprises.

\section{RESULTS OF THE RESEARCH}

Furtheremore, it is also possible to integrate the positive experience of the Mongolian scientific personnel training system through small innovative enterprises. Through these enterprises, the Ministry of Education and Science of Russia can accumulate information about innovation market challenges and, using these data, develop technological development forecasts and define promising science and technology development vectors. Based on the vectors received, formulate an order for breakthrough developments to the scientific community, which will strengthen practical orientation of thesis research.

However today, the significance of small innovative enterprises' contribution is greatly underestimated. There are a large number of barriers, impeding the implementation of the tasks, originally set for small innovative enterprises, as well as preventing full implementation of the potential embedded in these companies. In particular, methodologies, allowing the evaluation of the contribution of a specific small innovative enterprise as well as all small innovative enterprises, to the young scientific personnel training, and the evaluation of relative quality of this training, are not available. It can be unequivocally said that the practical consolidation of knowledge, obtained in higher educational institutions, while working in a small innovative enterprise is extremely important for a full-scale training of any specialist.

\section{References}

[1] Site of Russian Federal State Statistics Service, Link: http://www.gks.ru/

[2] Site of Germany Federal Statistical Office, Link: https://www.destatis.de/DE/Startseite.html

[3] Site of National Statistics Office of Mongolia, Link: http://1212.mn/

[4] Site of Agency of Kazakhstan of Statistics, Link: http://stat.gov.kz/faces/homePage?_afrLoop=2463412702898393\#\%40 \%3F_afrLoop\%3D2463412702898393\%26_adf.ctrlstate\%3D14mwddn9u0 282

[5] S.P. Ivanova, N.M. Rubtsov, M.V. Danilina, et al "Managing of smal and medium-sized trade enterprises: Efficiency increasing methods", International Journal of Economic Research, vol. 14, Issue 15, 2017 , Pages 407-422.

[6] A. Zimin, V. Otto, N. Filimonova, et al. "New Type of Regions in the Innovation Economy", Advanced science letters, v. 22, Is. 8, 2016, p. 2002-2006.

[7] M.N. Kulapov, M.N. Sidorov, P.A. Karasev, "Investments and economic growth: experience and mistakes of Russia", Russia: Investments and innovations, No. 3, 2014, p. 45-49.

[8] M.S. Bernafdo, A.F. Fernando, J.M. Joao, S.E. Carla, "Assesing the innovation capability of small- and medium-sized enterprises using a non-parametric and integritive approach", England: Management decision, V. 56, Is. 6, 2018, p. 1365-1383.

[9] E.V. Krotkova, A.R. Mullamekhametovna, "Innovative activity as a factor of anti-crisis development in the conditions of state support (on the example of Naberezhnye Chelny)", India: Helix, V. 8, Is. 1, 2018, p. 2908-2913.

[10] A.A. Safina, K.S. Kuramshina, "Features of management of innovative activity of small enterprises", India: Helix, V. 8, Is. 1, 2018, p. 29692974

[11] L. Khodov, "How start-ups in Germany are financed? Russia Contemporary europe - Sovremennaya Evropa", Is. 5, 2017, p 86-92

[12] E.L. Andreeva, H. Simon, D.A. Karkh, P.L. Glukhikh. "Innovative enterpreneurship: a source of economic growth in the region. Russia: Ekonomika regiona - Economy of region", v. 12, Is. 3, 2016, p. 899910.

[13] E. Ivanova, "Barriers to the development of SMEs in the Slovak Republic". Poland: Oeconomia copernicana, vol. 8, Is. 2, 2017, p. 255272 .

[14] S.V. Terebova, "The current state and specifics of small business development in Russia", Russia: Economic and social changes - Facts Trends Forecast, vol.10, Is. 1, 2017, p. 178-199.

[15] F. Mercandetti, C. Larbig, V. Tuozzo, T. Steiner. "Innovation by collaboration between Startups and SMEs in Switzerland", Canada: Technology innovation management review, vol. 7, Is. 12, 2017, p. 2331.

[16] M. Dabic, D. Vlajcic, I. Novak, "Enterpreneural management education needs in the Republic of Croatia, Poland and the United Kindom", England: International journal of educational management, vol. 30, Is. 6 , 2016, p. $738-755$ 